\title{
EEG spectral power and negative symptoms in at-risk individuals predict
}

\section{transition to psychosis}

\author{
*Ronan Zimmermann ${ }^{\text {a,b }}$, Ute Gschwandtner ${ }^{\mathrm{a}}$, Frank H. Wilhelm ${ }^{\mathrm{c}}$, Marlon O. \\ Pflueger $^{\mathrm{a}, \mathrm{b}}$, Anita Riecher-Rössler ${ }^{\mathrm{a}}$, Peter Fuhr ${ }^{\mathrm{b}}$ \\ ${ }^{a}$ University Psychiatric Outpatient Department, Psychiatric University Clinics Basel, \\ ${ }^{b}$ Department of Neurology, University Hospital, Basel, Switzerland, ${ }^{c}$ Faculty of Psychology, \\ Department of Clinical Psychology and Psychotherapy, University of Basel, Switzerland
}

*Equal Contribution

Corresponding author:

Prof. Dr. med. Peter Fuhr

Department of Neurology University Hospital Basel

Petersgraben 4-6

CH- 4031 Basel

Switzerland

E-Mail: fuhrp@uhbs.ch

Phone: 0041612654167

Fax: 0041612655644

E-Mails:

ZimmermannR@uhbs.ch

Ute.Gschwandtner@upkbs.ch

frank.wilhelm@unibas.ch

Marlon.Pflueger@upkbs.ch

Anita.Riecher@upkbs.ch

FuhrP@uhbs.ch 


\begin{abstract}
Objective: EEG power in the delta, theta and betal bands has been shown to be positively correlated with negative symptoms in first episode psychotic patients. The present study investigates this correlation in an "at risk mental state for psychosis" (ARMS) with the aim to improve prediction of transition to psychosis.
\end{abstract} Gelöscht: Introduction

Methods: Thirteen ARMS patients with later transition to psychosis (ARMS-T) and fifteen without (follow-up period of at least 4 years) (ARMS-NT) were investigated using spectral resting EEG data (of 8 electrodes over the fronto-central scalp area placed according to the 10 - 20 system) and summary score of the Scale for the Assessment of Negative Symptoms (SANS).

Linear regressions were used to evaluate the correlation of SANS and EEG power in seven bands (delta, theta, alpha1, alpha2, beta1, beta2, beta3) in both ARMS groups and logistic regressions were used to predict transition to psychosis. Potentially confounding factors were controlled.

Results: ARMS-T and ARMS-NT showed differential correlations of EEG power and SANS in delta, theta, and beta1 bands ( $\mathrm{p}<0.05)$ : ARMS-T showed positive and ARMS-NT negative correlations. Logistic regressions showed that neither SANS score nor EEG spectral power alone predicted transition to psychosis. However, SANS score in combination with power in the delta, theta, beta1, and beta 2 bands, respectively, predicted transition significantly ( $\mathrm{p}$ $<0.03)$

Limitations: The number of subjects is relatively small. The difference in age of both study groups might be considered as a further limitation even though age had no effect on the $\underline{\text { results according to confounder analysis. }}$

Conclusions: ARMS-T and ARMS-NT show differential correlations of SANS summary score and EEG power in delta, theta, and beta bands. Prediction of transition to psychosis is possible using combined information from a negative symptom scale and EEG spectral data. 
Keywords: schizophrenia, prediction, at risk mental state, quantitative EEG, negative symptoms, Fast Fourier Transform (FFT) 


\section{Introduction}

Ultra high risk studies aim at improving the early detection of psychosis in order to provide earlier and more efficient treatment to patients suffering from psychosis. ${ }^{1-2}$ Predominant criteria utilized to date are attenuated (sub-threshold) psychotic symptoms of brief limited psychotic episodes, genetic risk, and social decline. ${ }^{3}$ However, not all patients identified as being in an "at risk mental state for psychosis" (ARMS) by these criteria develop psychosis. The differentiation between ARMS patients who will make the transition to psychosis (ARMS-T) and ARMS patients who will not develop the disease (ARMS-NT) is of crucial importance. Recently reported transition-to-psychosis rates from our group were $34 \%^{4}$ and ranged from $9 \%$ to $54 \%$ in other high risk studies (see review by Olsen et al. . $^{5}$. Other recent studies suggest transition rates of about $15 \% .^{6-7}$ Thus, current criteria result in many 'false positives', which puts unnecessary burden on patients. Supplementary to the criteria of Yung et al. ${ }^{3}$ other risk factors have been detected that can potentially improve the identification of ARMS-T patients.

- ARMS-T patients are more severely impaired in certain neuropsychological domains compared to ARMS-NT patients and can be discriminated based on cognitive performances. ${ }^{8}$ For example, in a recent study of Riecher-Rössler et al. ${ }^{4}$ neuropsychological data were combined with psychopathological ratings (i.e., Brief Psychiatric Rating Scale, BPRS $)^{9}$ and Scale for the Assessment of Negative Symptoms (SANS) ${ }^{10}$ to enhance prediction of transition to psychosis.

- Neuroimaging studies (for review Wood et al.) ${ }^{11}$ detected structural changes in ARMS patients using structural magnetic resonance imaging. ${ }^{12}$ Koutsouleris et al. ${ }^{13}$ were able to classify ARMS-T patients with an accuracy of $88 \%$ using a multivariate wholebrain technique.

- Evoked potential studies have been conducted in ARMS patients (e.g. $\left.{ }^{14-16}\right)$. However, so far only Brockhaus-Dumke et al. ${ }^{17}$ compared ARMS-T with ARMS-NT. Their 
results indicate that N100 suppression evaluated in a double click paradigm is significantly reduced in ARMS-T $(\mathrm{p}<\underline{0.05})$, first episode $(\mathrm{FE}, \mathrm{p}<\underline{0.001)}$ ), as well as chronic patients $(\mathrm{p}<\underline{0} .001)$ compared to healthy controls but not ARMS-NT ( $\mathrm{p}=$ 0.052). However, ARMS-T and ARMS-NT did not differ on any of the studied parameters.

- Moreover, conventionally (non quantitatively) analyzed resting EEG was shown to increase the specificity of prediction of transition to psychosis in ARMS from 59\% to $73 \% .^{18}$

The present study tests the hypothesis that a combination of negative symptoms and spectral power of resting EEG increases predictive accuracy of transition to psychosis in ARMS patients. This hypothesis originates from the observation that negative symptoms and quantitative EEG (qEEG) spectral power are correlated in different types of medicated and unmedicated schizophrenic patients. ${ }^{19-27}$ Moreover, a recent study by our group ${ }^{28}$ showed that negative symptoms are positively correlated with qEEG absolute power in delta (0.5-4 Hz), theta $(4-8 \mathrm{~Hz})$ and betal $(12-15 \mathrm{~Hz})$ bands in the first episode (FE) of schizophrenia in neuroleptic-naïve patients. Presence of these correlations in neuroleptic naïve FE patients is a first requirement for the combination of negative symptoms with qEEG findings in ARMS patients to be a valid predictor for transition to psychosis. We expected to find correlations in the group of ARMS-T patients similar to those found in FE patients. A further requirement for the prediction of transition is absence of these correlations in ARMS-NT patients.

Thus, the objectives of the current study are to examine 1) whether the correlation of negative symptoms and EEG spectral power in ARMS-T patients is similar to that observed in the previously analyzed FE patients, but absent or different in ARMS-NT patients, and 2) whether it is possible to improve prediction of transition to psychosis in ARMS patients based on an increase of power in delta, theta, and beta1 frequency bands in combination with a negative symptom score (SANS). 


\section{Methods}

\section{Subjects}

Data from 13 ARMS-T and 15 ARMS-NT patients from the FEPSY (Early Detection of Psychosis) Clinic at the University Psychiatric Outpatient Department, Basel, Switzerland were analyzed. Baseline data including BPRS, SANS and EEG were collected at patients' first intake into clinic. Patients were then regularly followed-up. Criteria for ARMS and transition to psychosis were defined according to Yung et al. ${ }^{3}$ and are shown in Table 1 . The detailed screening process has been described elsewhere. ${ }^{4,29}$

\section{--- Insert Table 1 about here ---}

Exclusion criteria were age younger than 18 years, insufficient knowledge of German, IQ $<70$, previous episode of schizophrenic psychosis (treated with major tranquillizers for $>3$ weeks), psychosis clearly due to organic reasons or substance abuse, or psychotic symptoms within a clearly diagnosed depression or borderline personality disorder.

After complete description of the study to the subjects, written informed consent was obtained from all participants. The study was approved by the local ethics committee (Ethikkommission beider Basel, EKBB). A further condition for ARMS-NT patients was a follow-up period of at least four years. Four patients were on low dose neuroleptics (chloprothixen) prescribed for sedation, six patients were treated with antidepressive drugs (escitalopram, citalopram, paroxetine, sertralin, fluoxetin, venlafaxin) and three patients were on benzodiazepines (lorazepam, zolpidem). The patients' mean age was 25.7 (SD 7.6), 18 subjects were male and 10 were female. 


\section{Psychopathological ratings}

Patients were rated at study entry (baseline) with the Scale for the Assessment of Negative Symptoms (SANS) ${ }^{10}$ which consists of five subscales that evaluate aspects of negative symptoms (alogia, affective blunting, avolition-apathy, anhedonia-asociality, and attentional impairment). We calculated SANS summary score as described by Andreasen. ${ }^{30}$ Mean SANS summary score was 8.4 (SD 5.5, range 0-19). The variable was normally distributed.

\section{EEG data acquisition}

Only patients with a digitally recorded EEG at study entry ("baseline") were included. Routine EEG recordings of about 20 min duration were performed in a quiet room with closed eyes. Patients were instructed by the technicians to open eyes about every third minute for a period of five to six seconds. Additional open eyes segments were required if the patient showed signs of sleepiness.

EEG data were digitally recorded using 21 gold cup electrodes placed according to the international 10/20 system. Impedances were kept below $5 \mathrm{k} \Omega$. Amplifiers were calibrated using a $50 \mu \mathrm{V}$ square pulse. Sampling frequency was $250 \mathrm{~Hz}$. All channels were referenced to linked ears. EEGs were recorded with Alliance Works for Windows $\mathrm{NT}^{\mathrm{TM}}$ (Nicolet Biomedical Inc., Madison, Wisconsin). Raw EEG data were converted to European Data Format with Nicolet Data Converter (Nicolet Biomedical Inc., Madison, Wisconsin). Data were then read into Brain Vision Analyzer ${ }^{\odot}$ software (BVA; Brain Products GmbH, Munich, Germany). We selected 19 electrodes (Fp1, Fp2, F3, F4, C3, C4, P3, P4, O1, O2, F7, F8, T3, T4, T5, T6, Fz, Cz and Pz), recalculated the reference to average and set the high- and low 
pass (Butterworth) filters to $0.5-120 \mathrm{~Hz}$. We then removed eyes open sequences that had been marked by the technicians during the recording with the tool "Segmentation" of BVA.

\section{Artefact rejection}

To ensure high validity of the analysis Boutros et al. ${ }^{31}$ recommend a minimum of 25 artefact free segments of 2 seconds duration (see also Lund et al.). ${ }^{32}$ To conserve a maximum of EEG recording we used a semi-automatic standard operating procedure (SOP) to remove artefacts. The procedure consisted of three steps: 1) Continuous data containing obvious artefacts (e.g., electrode artefacts), except for those caused by eye movements, were manually deleted over all electrodes and remaining segments were juxtaposed. 2) In order to remove well defined sources of artefact, an independent component analysis (ICA) was performed with BVA. Once the independent time courses of different brain and artefact sources were extracted from the data, corrected EEG signals were computed by eliminating the contributions of the artefact sources. The ICA has been demonstrated to reliably isolate artefacts due to horizontal and vertical eye movements, heart electrical interference, and to some extent muscle or line noise. $^{33}$ 3) In a last step, the already corrected EEG was visually inspected by an experienced neurophysiologist who was blind to the patient's symptoms and diagnosis. He removed further artefacts not readily removed in steps 1 and 2 from the EEG recording, including muscle, movement and electrode artefacts. Patients with EEGs containing deeper sleep than stage A of Loomis et al. ${ }^{34}$ and with EEGs that showed EEG-identifiable pathologies (e.g., generalized epilepsy) were excluded from further analyses. After artefact removal, EEG recordings were divided into segments of two seconds. The remaining EEG recordings had a minimum length of 68 two-second-segments and an average length of $204.5 \mathrm{sec}(\mathrm{SD}=122)$.

\section{Analysis and statistics}


EEG power for all electrode sites was calculated using Fast Fourier Transform (FFT) (Hanning Window, 20\% taper length, $0.5 \mathrm{~Hz}$ bins from 0.5 to $30 \mathrm{~Hz}$ ) implemented in BVA. Data were exported into R-Software ${ }^{35}$ for statistical analysis. The FFT output data over the $0.5 \mathrm{~Hz}$ bins were combined to delta $(0.5-4 \mathrm{~Hz})$, theta $(4-8 \mathrm{~Hz})$, alpha1 $(8-10 \mathrm{~Hz})$, alpha2 $(10-12 \mathrm{~Hz})$, beta1 $(12-15 \mathrm{~Hz})$, beta2 $(15-25 \mathrm{~Hz})$ and beta3 $(25-30 \mathrm{~Hz})$ bands by calculating the mean of the corresponding $0.5 \mathrm{~Hz}$ frequency bins. Analyses were performed a-priori on average power of the 8 electrode sites used in our previous study, ${ }^{28}$ roughly covering the fronto-central half of the scalp (Fp1, F3, C3, Fz, Cz, Fp2, F4, C4). Other locations were not analyzed to minimize type I error. All EEG variables were transformed by natural logarithm to achieve normal distribution.

\section{Correlation of EEG spectral power with SANS scores in ARMS patients}

We performed one general linear regression per EEG band using absolute spectral power as dependent variable. Negative symptom score as well as group (ARMS-T vs. ARMS-NT) and the interaction term of group and negative symptom score were independent variables. We controlled for potential confounders (age, gender, use of benzodiazepines, use of antidepressants, use of low-dose neuroleptics, use of cannabis, and day time of EEG recording) by doing sensitivity analysis, i.e., we inserted the potentially confounding factors one by one into the regression models and checked whether the additional factor had relevant influence on the reported results.

To better illustrate the correlations of power and SANS for each group separately estimates and $95 \%$ confidence intervals (CI) were derived from mathematically equivalent stratified linear models with group-specific slopes of the negative symptoms variable (i.e., the respective group-specific terms were obtained by multiplying the original negative symptoms variable with the respective group indicator variable). 
To control for interindividual variability in EEG absolute power, we additionally calculated mixed effect models. ${ }^{36}$ For every band, power with a resolution of $0.5 \mathrm{~Hz}$ was used as dependent variable. Group and SANS score were used as fixed effects as in the general linear regression models. Intercept was used as random effect.

Prediction of transition to psychosis

To predict transition to psychosis using EEG power and SANS summary score collected at baseline, logistic regression models were calculated. ARMS status (T vs. NT) was used as dependent variable. Negative symptoms and EEG power (as well as the interaction of both variables) were used as independent variables. Finally, optimal cut-off scores for determining sensitivity, specificity, and prediction accuracy were calculated for the logistic regression models. 


\section{Results}

\section{Sample description}

Table 2 summarizes characteristics of the studied groups. While ARMS-T and ARMS-NT differed in age $(p=0.03)$ and while EEGs of both groups were recorded at different times of scht: One patient was excluded due to sleepiness during EEG recording, one due to persistent electrode and movemen day $(\mathrm{p}=0.02)$, no statistical difference could be found in terms of gender, medication, use of cannabis, intensity of negative symptoms, BPRS score and absolute power in different bands.

\section{--- Insert Table 2 about here ---}

\section{Correlation of EEG spectral power with SANS scores in ARMS patients}

Table 3 shows results of linear regression models describing the correlation between power in seven frequency bands and negative symptoms (SANS summary score) for both groups (ARMS-T vs. ARMS-NT).

\section{--- Insert Table 3 about here ---}

The significant interaction effect between negative symptoms and group indicates that the correlation of negative symptoms and power is differential in ARMS-T and ARMS-NT in the delta $(p=0.016)$, theta $(p=0.033)$, and beta1 $(p=0.036)$ bands.

In ARMS-NT power decreases in these bands with stronger negative symptoms (see estimates and CI in Table 3). In contrast, power of the ARMS-T group increases with stronger negative symptoms in the same bands (see Table 3 and Figure 1). 


\section{--- Insert Figure 1 about here ---}

\section{Influence of additional variables}

According to sensitivity analysis, none of the potentially confounding factors (including age and daytime of EEG recording) had significant effects on the discussed bands nor did any of them affect the reported results with the exception of intake of benzodiazepines which had a significant effect in the beta2 $(\mathrm{p}=0.029)$ and beta3 $(\mathrm{p}=0.006)$ bands. We redid the analysis excluding patients on benzodiazepines: The estimates of regression analysis did not relevantly change. A table with results of this sub-analysis can be seen in the supplemental material of the paper.

\section{Further analyses}

The results of the random effect procedure were similar to those of the linear regression models and can be seen in the supplemental material of the paper.

Comparison with first episode patients

In Figure 2, Spearman rank order correlation coefficients of the current analysis with ARMS patients are displayed together with those of FE patients described in our previous study. ${ }^{28}$ The figure shows that FE and ARMS-T patients exhibit a remarkably similar correlation pattern across the entire EEG frequency range. In contrast, the correlation coefficients of ARMS-NT patients are dissimilar and largely in the negative range. 


\section{--- Insert Figure 2 about here ---}

\section{Prediction of transition to psychosis}

Neither SANS nor EEG power scores alone were predictive for transition to psychosis. Results of logistic regression models combining negative symptoms and power are presented in Table 4 . The models for the delta, theta, beta1 and beta2 bands had statistically significant predictive power $(\mathrm{p}<0.05)$. Within these models the interaction terms (of power and negative symptoms) were significant $(\mathrm{p}<0.05)$ as well as the main effects of negative symptoms in models theta, beta1 and beta2.

\section{--- Insert Table 4 about here ---}

Table 4 also lists Nagelkerke's $\mathrm{R}^{2}$ index, optimal probability cut-off scores, the percentage of correctly classified patients, sensitivity and specificity as well as positive and negative predictive values. Best prediction of transition to psychosis was reached with the model combining negative symptoms with power in the theta band with $89 \%$ correct classifications. Also the models combing SANS summary score and power in delta, beta1 and beta 2 bands showed high predictive accuracy $(\mathrm{PPC}>0.80)$. 


\section{Discussion}

The first objective was to investigate whether the positive correlations of EEG power in the delta, theta, and beta1 bands with negative symptoms, previously observed in FE patients, ${ }^{28}$ are already present before the clinical outbreak (in ARMS-T patients). Direction and degree of these correlations in ARMS-T patients are almost equivalent to those observed in FE patients (see Table 3), although confidence intervals were not clearly in the positive range, probably due to small sample size $(\mathrm{N}=13)$. In ARMS-NT, in contrast, correlations of power in these bands with negative symptoms were clearly negative. Thus, the correlation pattern of ARMS-NT patients was almost a mirror image to that of ARMS-T and FE (see Figure 2). Interaction terms of linear regression analyses indicated that correlations of SANS summary score and power in delta, theta, and beta1 bands differed significantly between ARMS-T and ARMS-NT. Therefore, the first hypothesis of the study, stating that the relationship of negative symptoms and EEG spectral power in ARMS-T patients is similar to that observed in FE, but different in ARMS-NT patients, is largely confirmed.

The second objective was to assess the accuracy of models comprising SANS and qEEG data for prediction of transition of ARMS patients to psychosis. Logistic regression models showed significant predictions for delta, theta, beta1, and surprisingly, for the beta2 band (see Table 4). The models classified transition to psychosis in ARMS patients with an accuracy of over $80 \%$. Therefore, the second hypothesis, stating that it is possible to improve prediction of transition to psychosis in ARMS patients based on power in delta, theta, and beta1 bands in combination with the SANS score, is confirmed. The study suggests that EEG spectral analysis in combination with SANS score might be helpful in predicting transition or nontransition to psychosis in ARMS.

Other applications are conceivable: Currently efforts are made to increasingly base future classification systems of psychoses on biological data. ${ }^{37}$ The positive correlations of EEG 
power and negative symptoms have been observed in chronic stages of schizophrenia, ${ }^{20,23,25}$, ${ }^{27}$ in FE patients ${ }^{28}$ and with the present study also in the prodromal phase of psychosis (ARMS-T) while the same correlations showed sign reversal in a non-psychotic control group (ARMS-NT). QEEG data might, thus, represent an endophenotype ${ }^{38}$ associated with behavioral symptoms and could, therefore, be helpful in the differential diagnosis of disorders with negative symptoms.

The associating of higher EEG power in low frequency bands with stronger negative symptoms in schizophrenic patients might be due to a lack of activity in non-motor corticobasalganglionic-thalamo-cortical circuits as proposed for negative symptom like signs and EEG alterations in Parkinson's disease. ${ }^{39-41}$ Speculation about the mechanism underlying the sign reversed correlation in the control group is, however, difficult at this stage.

The current study represents an initial foray into a vital clinical field. Up to now, the question of the specificity of the phenomenon has not been sufficiently investigated and, therefore, studies including different pathological control populations and, additionally, studies with repeated assessment of qEEG in high-risk populations, including patients under the age of 18 , to address the question whether EEG alterations represent a state or a trait marker are warranted. Although results are probably not affected by any confounding factors as shown by carefully conducted sensitivity analyses, future studies should make efforts to investigate these phenomena in samples that are comparable in age, which could not be done in the present study. 
Table 1: Criteria for ARMS and transition to psychosis

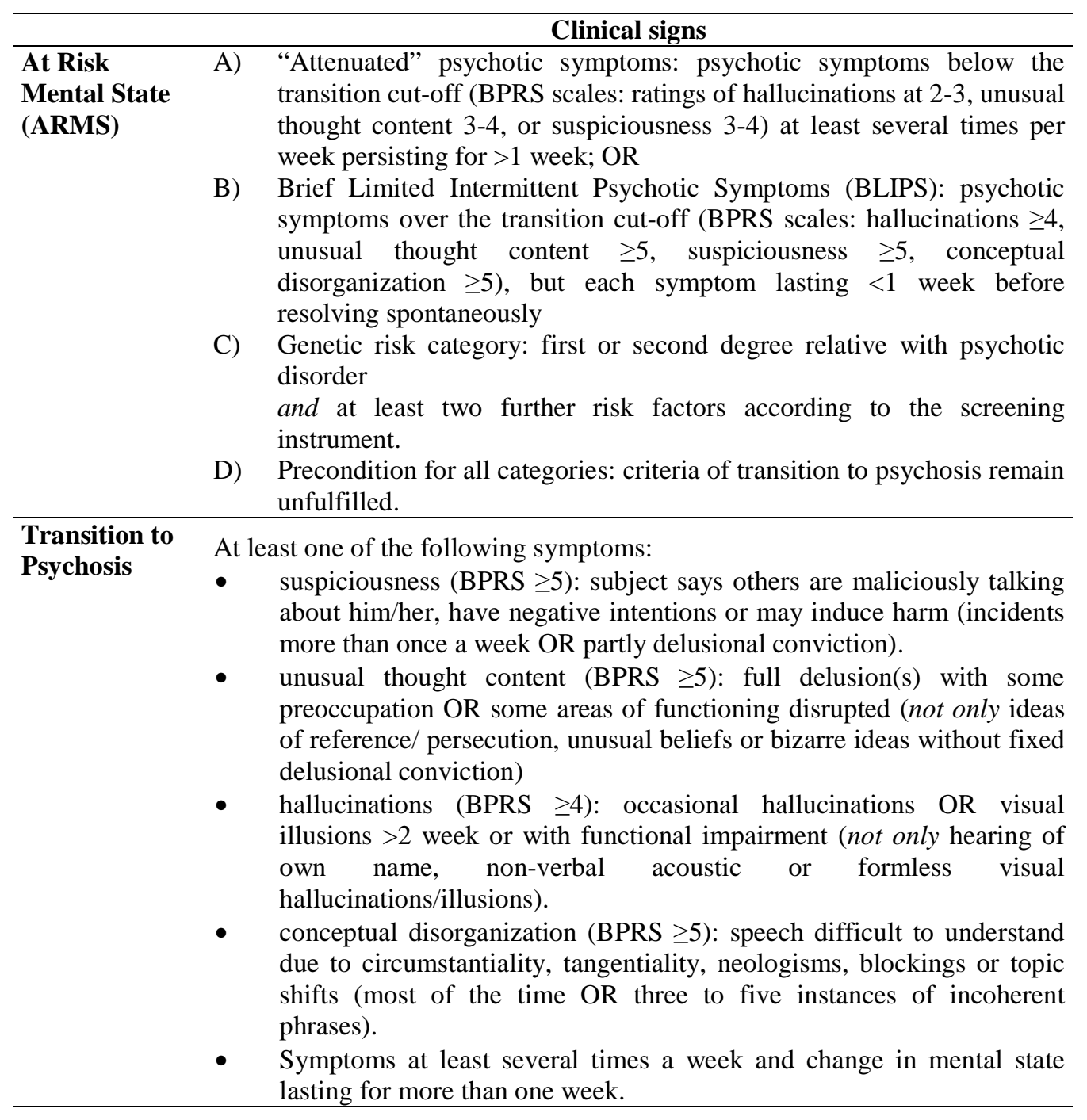

Note: BPRS = Brief Psychiatric Rating Scale (Lukoff, 1986) 
Table 2: Demographic and clinical characteristics of ARMS-T vs. ARMS-NT patient groups at baseline

\begin{tabular}{|c|c|c|c|}
\hline & ARMS-NT & ARMS-T & Inferential statistic \\
\hline $\mathbf{N}$ & 15 & 13 & \\
\hline Gender (male) & $66.6 \%$ & $61.5 \%$ & ${ }^{*} \mathrm{p}=1$ \\
\hline Age, mean (SD) years & $23.1(6.9)$ & $28.7(7.5)$ & ${ }^{\dagger} \mathrm{W}=50 ; \mathrm{p}=0.003$ \\
\hline High dose neuroleptics & $0 \%$ & $0 \%$ & Not available \\
\hline Low dose neuroleptics & $13.3 \%$ & $15.4 \%$ & ${ }^{*} \mathrm{p}=1$ \\
\hline Antidepressants & $20 \%$ & $23.1 \%$ & ${ }^{*} \mathrm{p}=1$ \\
\hline Benzodiazepines & $6.7 \%$ & $15.4 \%$ & ${ }^{*} \mathrm{p}=0.58$ \\
\hline Mood stabilizer & $0 \%$ & $7.7 \%$ & ${ }^{*} \mathrm{p}=0.46$ \\
\hline \multicolumn{4}{|l|}{ Cannabis use } \\
\hline no & 10 & 8 & \multirow{5}{*}{$\begin{array}{c}\chi^{\ddagger}(\mathrm{df}=3)=0.13 \\
\mathrm{p}=0.73\end{array}$} \\
\hline less than monthly & 0 & 0 & \\
\hline monthly & 1 & 0 & \\
\hline weekly & 2 & 3 & \\
\hline daily & 2 & 2 & \\
\hline $\begin{array}{l}\text { Day time of EEG } \\
\text { recording (SD) }\end{array}$ & $10.2(2.1)$ & $13(3)$ & ${ }^{\ddagger} \mathrm{W}=49 ; \mathrm{p}=0.002$ \\
\hline $\begin{array}{l}\text { SANS global score, } \\
\text { mean (SD) }\end{array}$ & $7.6(5.7)$ & $9.4(5.3)$ & $\begin{array}{c}\S_{\mathrm{t}}(\mathrm{df}=25.8)=-0.86 \\
\mathrm{p}=0.40\end{array}$ \\
\hline $\begin{array}{l}\text { BPRS summary score, } \\
\text { mean (SD) }\end{array}$ & $38.6(10.1)$ & $41.6(9.1)$ & $\begin{array}{c}\S_{\mathrm{t}}(\mathrm{df}=25.9)=-0.76 \\
\mathrm{p}=0.46\end{array}$ \\
\hline \multicolumn{4}{|l|}{ EEG power } \\
\hline $\begin{array}{l}\text { delta }(0.5-4 \mathrm{~Hz}, \log ) \\
\text { mean }(\mathrm{SD})\end{array}$ & $0.13(0.47)$ & $0.1(0.38)$ & $\begin{array}{c}{ }^{8} \mathrm{t}(\mathrm{df}=25.9)=0.17 \\
\mathrm{p}=0.86\end{array}$ \\
\hline $\begin{array}{l}\text { theta }(4-8 \mathrm{~Hz}, \log ) \\
\text { mean }(\mathrm{SD})\end{array}$ & $-0.91(0.6)$ & $-0.78(0.72)$ & $\begin{array}{c}\S_{\mathrm{t}}(\mathrm{df}=23.6)=-0.50 \\
\mathrm{p}=0.62\end{array}$ \\
\hline $\begin{array}{l}\text { alpha1 }(8-10 \mathrm{~Hz}, \log ) \\
\text { mean }(\mathrm{SD})\end{array}$ & $-0.47(0.99)$ & $0.19(1.16)$ & $\begin{array}{c}{ }^{\$_{\mathrm{t}}} \mathrm{d}(\mathrm{df}=23.8)=-1.60 \\
\mathrm{p}=0.12\end{array}$ \\
\hline $\begin{array}{l}\text { alpha2 }(10-12 \mathrm{~Hz}, \log ), \\
\text { mean }(\mathrm{SD})\end{array}$ & $0.19(1.05)$ & $-0.09(0.96)$ & 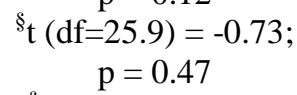 \\
\hline $\begin{array}{l}\text { beta1 }(12-15 \mathrm{~Hz}, \log ) \text {, } \\
\text { mean }(\mathrm{SD})\end{array}$ & $-1.33(0.77)$ & $-0.128(0.68)$ & $\begin{array}{c}\S_{\mathrm{t}}(\mathrm{df}=26)=-0.19 \\
\mathrm{p}=0.85\end{array}$ \\
\hline $\begin{array}{l}\text { beta2 }(15-25 \mathrm{~Hz}, \log ), \\
\text { mean }(\mathrm{SD})\end{array}$ & $-2.01(0.65)$ & $-1.86(0.68)$ & $\begin{array}{c}\S_{\mathrm{t}}(\mathrm{df}=25.0)=-0.83 ; \\
\mathrm{p}=0.41\end{array}$ \\
\hline $\begin{array}{l}\text { beta } 3(25-30 \mathrm{~Hz}, \log ), \\
\text { mean }(\mathrm{SD})\end{array}$ & $-2.73(0.63)$ & $-2.41(0.82)$ & $\begin{array}{c}\S_{\mathrm{t}}(\mathrm{df}=22.5)=-1.2 \\
\mathrm{p}=0.25\end{array}$ \\
\hline
\end{tabular}

*Fisher's exact test for Count Data; 'Wilcoxon rank sum test with continuity correction; †Pearson's Chi-squared Test for Count Data; ${ }^{\S}$ Student's t-Test. "Log" indicates that variable was transformed by natural logarithm. 
Table 3: Results of linear regression analysis

\begin{tabular}{|c|c|c|c|c|}
\hline \multirow{2}{*}{$\begin{array}{l}\text { qEEG spectral band } \\
\text { Delta (Overall Model) }\end{array}$} & \multicolumn{2}{|c|}{$\begin{array}{c}\text { Estimate } \\
{[\mathrm{b}]}\end{array}$} & \multirow[t]{2}{*}{ [CI 95\%] } & \multirow[t]{2}{*}{$\begin{array}{l}\text { p-value of } \\
\text { interaction }\end{array}$} \\
\hline & & & & \\
\hline Negative symptoms of ARMS-T & $\mathrm{b}=$ & 0.12 & {$[-0.10,0.35]$} & \\
\hline Negative symptoms of ARMS-NT & $\mathrm{b}=$ & -0.26 & {$[-0.45,-0.07]$} & \\
\hline \multicolumn{5}{|l|}{ Theta (Overall Model) } \\
\hline Negative symptoms of ARMS-T & $\mathrm{b}=$ & 0.24 & {$[-0.13,0.60]$} & \multirow{2}{*}{0.033} \\
\hline Negative symptoms of ARMS-NT & $\mathrm{b}=$ & -0.31 & {$[-0.62,0.00]$} & \\
\hline \multicolumn{5}{|l|}{ Alpha1 (Overall Model) } \\
\hline Negative symptoms of ARMS-T & $\mathrm{b}=$ & 0.13 & {$[-0.54,0.80]$} & \multirow{2}{*}{0.331} \\
\hline Negative symptoms of ARMS-NT & $\mathrm{b}=$ & -0.32 & {$[-0.90,0.25]$} & \\
\hline \multicolumn{5}{|l|}{ Alpha2 (Overall Model) } \\
\hline Negative symptoms of ARMS-T & $\mathrm{b}=$ & 0.14 & {$[-0.47,0.75]$} & \multirow{2}{*}{0.323} \\
\hline Negative symptoms of ARMS-NT & $\mathrm{b}=$ & -0.24 & {$[-0.76,0.28]$} & \\
\hline \multicolumn{5}{|l|}{ Beta1 (Overall Model) } \\
\hline Negative symptoms of ARMS-T & $\mathrm{b}=$ & 0.20 & {$[-0.20,0.60]$} & \multirow{2}{*}{0.036} \\
\hline Negative symptoms of ARMS-NT & $\mathrm{b}=$ & -0.39 & {$[-0.73,-0.05]$} & \\
\hline \multicolumn{5}{|l|}{ Beta2 (Overall Model) } \\
\hline Negative symptoms of ARMS-T & $\mathrm{b}=$ & 0.09 & {$[-0.30,0.48]$} & \multirow{2}{*}{0.175} \\
\hline Negative symptoms of ARMS-NT & $\mathrm{b}=$ & -0.27 & {$[-0.61,0.06]$} & \\
\hline \multicolumn{5}{|l|}{ Beta3 (Overall Model) } \\
\hline Negative symptoms of ARMS-T & $\mathrm{b}=$ & -0.07 & {$[-0.52,0.38]$} & \multirow{2}{*}{0.933} \\
\hline Negative symptoms of ARMS-NT & $\mathrm{b}=$ & -0.06 & {$[-0.45,0.32]$} & \\
\hline
\end{tabular}

Note: Table 3 shows group specific estimates and confidence intervals of the correlation of EEG power and SANS summary score in seven frequency bands derived from stratified linear models. P-value of interactions of negative symptoms with group indicates if the correlation in the respective band behaves differently according to group (ARMS-T vs. ARMS-NT). 
Table 4: Results of logistic regression analysis

\begin{tabular}{|c|c|c|c|c|c|c|c|c|c|c|}
\hline Variables & Estimate & Std. Error & \multicolumn{2}{|c|}{ Statistic } & \multirow{2}{*}{$\begin{array}{c}\text { p-value } \\
0.024\end{array}$} & \multirow[t]{2}{*}{$\mathbf{R}^{2}$} & \multirow[t]{2}{*}{$\begin{array}{l}\text { Cut- } \\
\text { off }\end{array}$} & \multirow[t]{2}{*}{ PCC } & \multirow[t]{2}{*}{$\begin{array}{l}\text { Sens } \\
\text { Spec }\end{array}$} & \multirow[t]{2}{*}{$\begin{array}{l}\text { PPV } \\
\text { NPV }\end{array}$} \\
\hline & & & & & & & & & & \\
\hline Delta absolute power & $\mathrm{b}=\lfloor-0.51$ & 1.29 & $\underline{z} \equiv$ & -0.39 & 0.694 & \multirow{3}{*}{-0.38} & \multirow{3}{*}{-0.40} & \multirow{3}{*}{0.82} & \multirow{3}{*}{-0.92} & \multirow{3}{*}{$\begin{array}{r}0.75 \\
-0.92\end{array}$} \\
\hline Negative symptoms & $b=-0.09$ & 0.54 & $z=$ & -0.17 & 0.867 & & & & & \\
\hline Interaction (Power*Negative Symptoms) & $b=4.08$ & 1.81 & $z=$ & 2.26 & 0.024 & & & & & \\
\hline Model Theta & & & & & 0.001 & \multirow{4}{*}{0.58} & \multirow{4}{*}{0.35} & \multirow{4}{*}{0.89} & \multirow{4}{*}{$\begin{array}{l}0.92 \\
0.87\end{array}$} & \multirow{4}{*}{$\begin{array}{l}0.86 \\
0.93\end{array}$} \\
\hline Theta absolute power & $b=0.31$ & 1.03 & $z=$ & 0.30 & 0.761 & & & & & \\
\hline Negative symptoms & $b=6.17$ & 2.47 & $z=$ & 2.50 & 0.012 & & & & & \\
\hline Interaction (Power*Negative Symptoms) & $b=5.96$ & 2.48 & $z=$ & 2.41 & 0.016 & & & & & \\
\hline Model Alpha1 & & & & & 0.097 & \multirow{4}{*}{0.27} & \multirow{4}{*}{0.61} & \multirow{4}{*}{0.71} & \multirow{4}{*}{$\begin{array}{l}0.46 \\
0.93\end{array}$} & \multirow{4}{*}{$\begin{array}{l}0.86 \\
0.67\end{array}$} \\
\hline Alpha1 absolute power & $b=0.62$ & 0.46 & $z=$ & 1.36 & 0.174 & & & & & \\
\hline Negative Symptoms & $b=0.95$ & 0.59 & $z=$ & 1.61 & 0.108 & & & & & \\
\hline Interaction (Power^Negative Symptoms) & $b=0.90$ & 0.64 & $z=$ & 1.41 & 0.158 & & & & & \\
\hline Model Alpha2 & & & & & 0.556 & \multirow{4}{*}{0.01} & \multirow{4}{*}{0.50} & \multirow{4}{*}{0.71} & \multirow{4}{*}{$\begin{array}{l}0.69 \\
0.73\end{array}$} & \multirow{4}{*}{$\begin{array}{l}0.69 \\
0.73\end{array}$} \\
\hline Alpha2 absolute power & $b=-0.18$ & 0.43 & $z=$ & -0.41 & 0.680 & & & & & \\
\hline Negative Symptoms & $b=0.34$ & 0.40 & $z=$ & 0.84 & 0.399 & & & & & \\
\hline Interaction (Power*Negative Symptoms) & $b=0.38$ & 0.42 & $z=$ & 0.89 & 0.372 & & & & & \\
\hline Model Beta1 & & & & & 0.041 & \multirow{4}{*}{0.34} & \multirow{4}{*}{0.44} & & & \\
\hline Beta1 absolute power & $b=0.79$ & 0.74 & $z=$ & 1.07 & 0.283 & & & 082 & 0.92 & 0.75 \\
\hline Negative Symptoms & $b=3.13$ & 1.34 & $z=$ & 2.34 & 0.019 & & & & 0.73 & 0.92 \\
\hline Interaction (Power*Negative Symptoms) & $b=1.82$ & 0.79 & $z=$ & 2.32 & 0.021 & & & & & \\
\hline Model Beta2 & & & & & 0.032 & & & & & \\
\hline Beta2 absolute power & $b=0.51$ & 0.77 & $z=$ & 0.66 & 0.508 & 0.36 & 0.43 & 0.82 & 0.85 & 0.79 \\
\hline Negative Symptoms & $b=6.81$ & 3.09 & $z=$ & 0.20 & 0.028 & & & & 0.80 & 0.86 \\
\hline Interaction (Power*Negative Symptoms) & $b=2.88$ & 1.33 & $z=$ & 0.17 & 0.030 & & & & & \\
\hline Model Beta3 & & & & & 0.457 & & & & & \\
\hline Beta3 absolute power & $b=0.84$ & 0.71 & $z=$ & 1.19 & 0.235 & 0.12 & 0.45 & 0.75 & 0.77 & 0.71 \\
\hline Negative Symptoms & $b=0.00$ & 2.64 & $z=$ & 0.00 & 0.999 & 0.12 & 0.45 & 0.170 & 0.73 & 0.79 \\
\hline Interaction (Power*Negative Symptoms) & $b=-0.15$ & 0.97 & $z=$ & -0.15 & 0.879 & & & & & \\
\hline
\end{tabular}

Note: Table 4 shows results of logistic regression models predicting transition to psychosis in ARMS patients based on the combination of negative symptom score and power scores in seven frequency bands. The last columns of the table show Nagelkerke's $\mathrm{R}^{2}$ index, the optimal cut-off values, percentage of correctly classified individuals (PCC), sensitivity and specificity as well as positive predictive values (PPV) and negative predictive values (NPV) for the logistic regressions. 


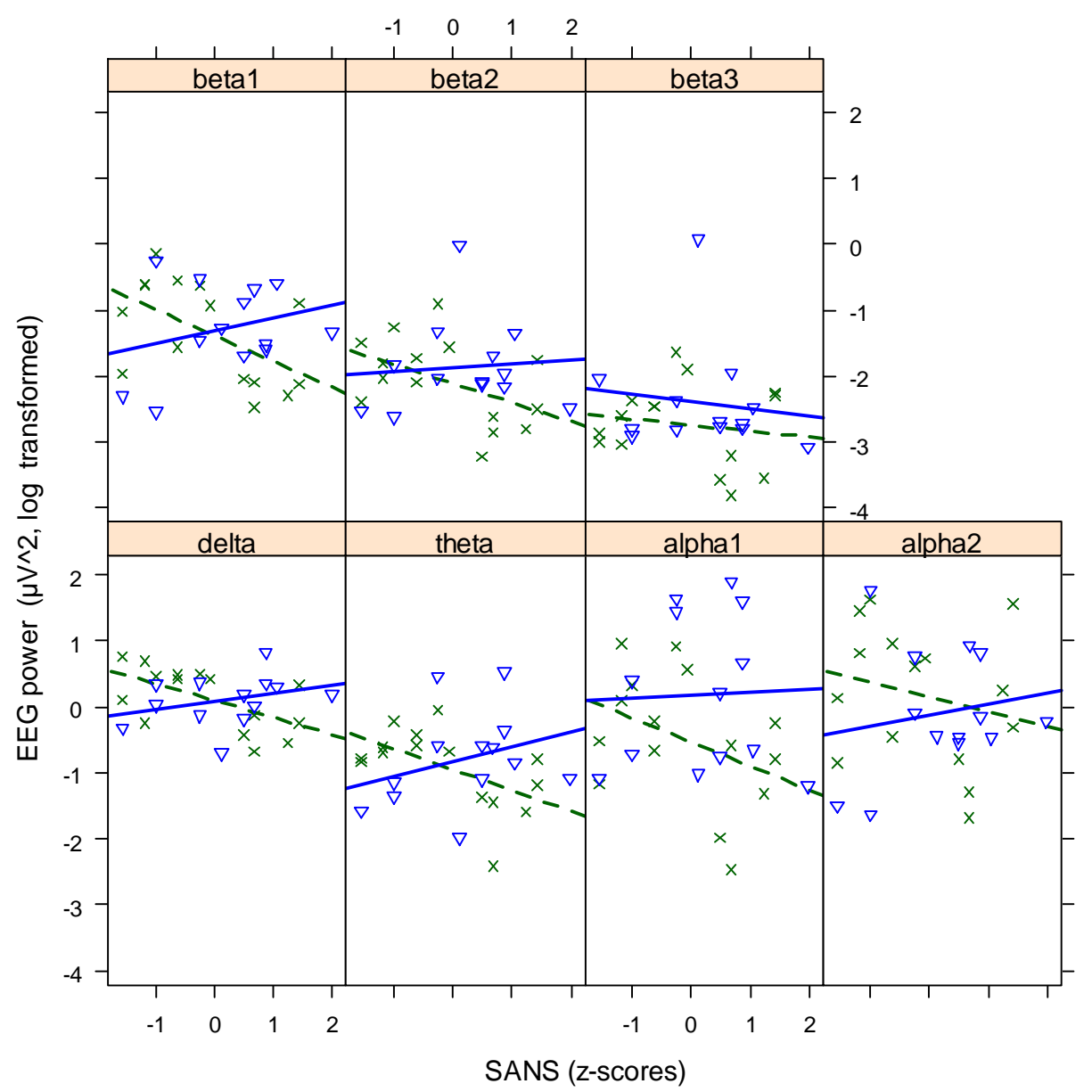

Figure 1 Scatterplots of negative symptoms (SANS summary scores, z-transformed) and EEG power in seven frequency bands for ARMS-T $(\Delta)$ and ARMS-NT (x) patients 


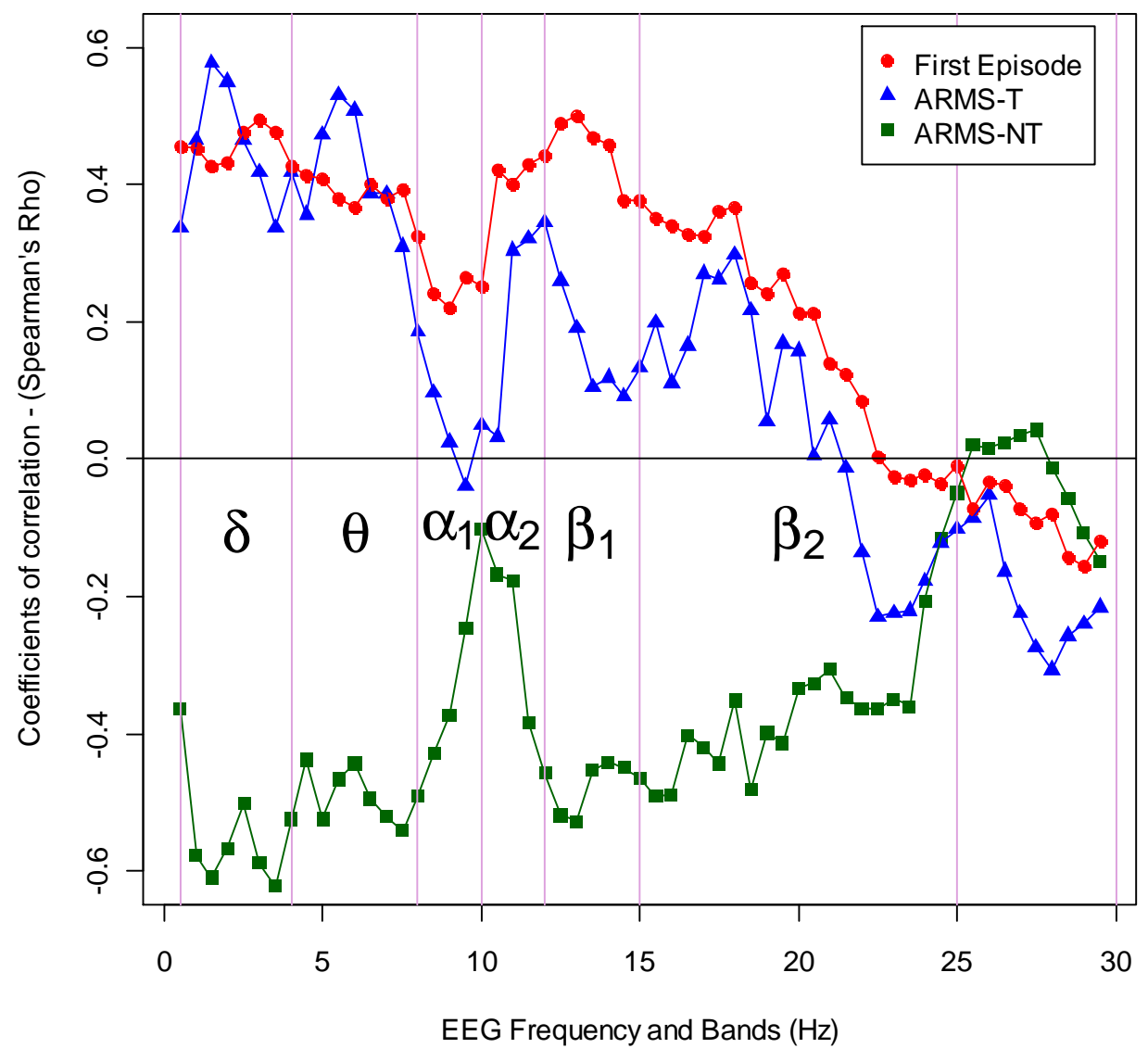

Figure 2 Correlation coefficients of EEG spectral power at different frequencies with SANS summary scores for ARMS-T and ARMS-NT patients. Greek letters represent the bands as they were defined for the linear regression analysis. Results of first episode (FE) patients ${ }^{28}$ are displayed for comparison. $59 \%$ of FE patients were male, mean age was 32 years $(9.8$ SD), 3 were on antidepressants, 4 on benzodiazepines, 8 used cannabis. Mean SANS summary score in FE patients was 7.4 (4.6 SD). 


\section{Literatur}

1. McGorry PD, Killackey E, Yung A. Early intervention in psychosis: concepts, evidence and future directions. World Psychiatry. 2008;7(3):148-56.

2. Riecher-Rössler A, Gschwandtner U, Borgwardt S, et al. Early detection and treatment of schizophrenia: how early? Acta Psychiatr Scand Suppl. 2006(429):73-80.

3. Yung AR, Phillips LJ, McGorry PD, et al. Prediction of psychosis. A step towards indicated prevention of schizophrenia. Br J Psychiatry Suppl. 1998;172(33):14-20.

4. Riecher-Rössler A, Pflueger MO, Aston J, et al. Efficacy of using cognitive status in predicting psychosis: a 7-year follow-up. Biol Psychiatry. 2009;66(11):1023-30.

5. Olsen KA, Rosenbaum B. Prospective investigations of the prodromal state of schizophrenia: assessment instruments. Acta Psychiatr Scand. 2006;113(4):273-82.

6. Simon AE, Umbricht D. High remission rates from an initial ultra-high risk state for psychosis. Schizophr Res. 2010;116(2-3):168-72.

7. Yung AR, Nelson B, Stanford C, et al. Validation of "prodromal" criteria to detect individuals at ultra high risk of psychosis: 2 year follow-up. Schizophr Res. 2008;105(1-3):10-7.

8. Pukrop R, Ruhrmann S, Schultze-Lutter F, et al. Neurocognitive indicators for a conversion to psychosis: comparison of patients in a potentially initial prodromal state who did or did not convert to a psychosis. Schizophr Res. 2007;92(1-3):116-25.

9. Lukoff DN. Manual for the expanded brief psychiatric rating scale. Schizophr Bull. 1986;12:594-602.

10. Andreasen NC. The Scale for the Assessment of Negative Symptoms (SANS): conceptual and theoretical foundations. Br J Psychiatry Suppl. 1989(7):49-58.

11. Wood SJ, Pantelis C, Velakoulis D, et al. Progressive changes in the development toward schizophrenia: studies in subjects at increased symptomatic risk. Schizophr Bull. 2008;34(2):322-9.

12. Borgwardt SJ, McGuire PK, Aston J, et al. Structural brain abnormalities in individuals with an at-risk mental state who later develop psychosis. Br J Psychiatry Suppl. 2007;51:s69-75.

13. Koutsouleris N, Meisenzahl EM, Davatzikos C, et al. Use of neuroanatomical pattern classification to identify subjects in at-risk mental states of psychosis and predict disease transition. Arch Gen Psychiatry. 2009;66(7):700-12.

14. Bramon E, Shaikh M, Broome M, et al. Abnormal P300 in people with high risk of developing psychosis. Neuroimage. 2008;41(2):553-60.

15. Cadenhead KS, Light GA, Shafer KM, et al. P50 suppression in individuals at risk for schizophrenia: the convergence of clinical, familial, and vulnerability marker risk assessment. Biol Psychiatry. 2005;57(12):1504-9.

16. Frommann I, Brinkmeyer J, Ruhrmann S, et al. Auditory P300 in individuals clinically at risk for psychosis. Int J Psychophysiol. 2008;70(3):192-205.

17. Brockhaus-Dumke A, Schultze-Lutter F, Mueller R, et al. Sensory gating in schizophrenia: P50 and N100 gating in antipsychotic-free subjects at risk, firstepisode, and chronic patients. Biol Psychiatry. 2008;64(5):376-84.

18. Gschwandtner U, Pflueger MO, Semenin V, et al. EEG: a helpful tool in the prediction of psychosis. Eur Arch Psychiatry Clin Neurosci. 2009;259(5):257-62.

19. Gattaz WF, Mayer S, Ziegler P, et al. Hypofrontality on topographic EEG in schizophrenia. Correlations with neuropsychological and psychopathological parameters. Eur Arch Psychiatry Clin Neurosci. 1992;241(6):328-32.

20. Gerez M, Tello A. Selected quantitative EEG (QEEG) and event-related potential (ERP) variables as discriminators for positive and negative schizophrenia. Biol Psychiatry. 1995;38(1):34-49. 
21. Merrin EL, Floyd TC. Negative symptoms and EEG alpha in schizophrenia: a replication. Schizophr Res. 1996;19(2-3):151-61.

22. Harris AW, Williams L, Gordon E, et al. Different psychopathological models and quantified EEG in schizophrenia. Psychol Med. 1999;29(5):1175-81.

23. Sponheim SR, Clementz BA, Iacono WG, et al. Clinical and biological concomitants of resting state EEG power abnormalities in schizophrenia. Biol Psychiatry. 2000;48(11):1088-97.

24. Winterer G, Ziller M, Dorn H, et al. Frontal dysfunction in schizophrenia--a new electrophysiological classifier for research and clinical applications. Eur Arch Psychiatry Clin Neurosci. 2000;250(4):207-14.

25. Gross A, Joutsiniemi SL, Rimon R, et al. Correlation of symptom clusters of schizophrenia with absolute powers of main frequency bands in quantitative EEG. Behav Brain Funct. 2006;2:23.

26. John ER, Prichep LS, Winterer G, et al. Electrophysiological subtypes of psychotic states. Acta Psychiatr Scand. 2007;116(1):17-35.

27. Venables NC, Bernat EM, Sponheim SR. Genetic and disorder-specific aspects of resting state EEG abnormalities in schizophrenia. Schizophr Bull. 2009;35(4):826-39.

28. Gschwandtner U, Zimmermann R, Pflueger MO, et al. Negative symptoms in neuroleptic-naive patients with first-episode psychosis correlate with QEEG parameters. Schizophr Res. 2009;115(2-3):231-6.

29. Riecher-Rössler A, Gschwandtner U, Aston J, et al. The Basel early-detection-ofpsychosis (FEPSY)-study--design and preliminary results. Acta Psychiatr Scand. 2007;115(2):114-25.

30. Andreasen NC. Negative symptoms in schizophrenia. Definition and reliability. Arch Gen Psychiatry. 1982;39(7):784-8.

31. Boutros NN, Arfken C, Galderisi S, et al. The status of spectral EEG abnormality as a diagnostic test for schizophrenia. Schizophr Res. 2008;99(1-3):225-37.

32. Lund TR, Sponheim SR, Iacono WG, et al. Internal consistency reliability of resting EEG power spectra in schizophrenic and normal subjects. Psychophysiology. 1995;32(1):66-71.

33. Jung TP, Makeig S, Humphries C, et al. Removing electroencephalographic artifacts by blind source separation. Psychophysiology. 2000;37(2):163-78.

34. Loomis AL, Harvey EN, Hobart G. Cerebral states during sleep, as studied during human brain potentials. J Exp Psychol. 1937:127-44.

35. R Development Core Team. A language and environment for statistical computing. $\mathrm{R}$ Foundation for Statistical Computing, Vienna, Austria. 2009. Available from: http://www.R-project.org.

36. Baayen RH, Davidson DJ, Bates DM. Mixed effects modeling with crossed random effects for subjects and items. J Mem Lang. 2008;59:390-412.

37. Gaebel W, Zielasek J. Future classification of psychotic disorders. Eur Arch Psychiatry Clin Neurosci. 2009;259 Suppl 2:S213-8.

38. Gottesman, II, Gould TD. The endophenotype concept in psychiatry: etymology and strategic intentions. Am J Psychiatry. 2003;160(4):636-45.

39. Soikkeli R, Partanen J, Soininen H, et al. Slowing of EEG in Parkinson's disease. Electroencephalogr Clin Neurophysiol. 1991;79(3):159-65.

40. Rodriguez-Oroz MC, Jahanshahi M, Krack P, et al. Initial clinical manifestations of Parkinson's disease: features and pathophysiological mechanisms. Lancet Neurol. 2009;8(12):1128-39.

41. Caviness JN, Hentz JG, Evidente VG, et al. Both early and late cognitive dysfunction affects the electroencephalogram in Parkinson's disease. Parkinsonism Relat Disord. 2007;13(6):348-54. 